\title{
REACTION MECHANISMS OF MAGNESIUM SILICATES WITH CARBON DIOXIDE IN MICROWAVE FIELDS
}

Final Report to the U.S. Department of Energy, National Energy Technology Laboratory

For the Period September 1, 2002 through November 28, 2003

William B. White

Michael R. Silsbee

B Joe Kearns

Report Issued February 18, 2004

Award No. DE-FG26-02NT41545

Materials Research Institute

The Pennsylvania State University

University Park, PA 16802 


\section{DISCLAIMER}

This report was prepared as an account of work sponsored by an agency of the United States Government. Neither the United States Government nor any agency thereof, nor any of their employees, makes any warranty, express or implied, or assumes any legal liability or responsibility for the accuracy, completeness, or usefulness of any information, apparatus, product, or process disclosed, or represents that its use would not infringe privately owned rights. Reference herein to any specific commercial product, process, or service by trade name, trademark, manufacturer, or otherwise does not necessarily constitute or imply its endorsement, recommendation, or favoring by the United States Government or any agency thereof. The views and opinions of authors expressed herein do not necessarily state or reflect those of the United States Government or any agency thereof. 


\begin{abstract}
The objective of the investigation was to determine whether microwave fields would enhance the reactions of $\mathrm{CO}_{2}$ with silicates that are relevant to the sequestration of carbon dioxide. Three sets of experiments were conducted. (1) Serpentine and $\mathrm{CO}_{2}$ were reacted directly at one atmosphere pressure in a microwave furnace. Little reaction was observed. (2) Serpentine was dehydroxylated in a microwave furnace. The reaction was rapid, reaching completion in less than 30 minutes. A detailed investigation of this reaction produced an S-shaped kinetics curve, similar to the kinetics from dehydroxylating serpentine in a resistance furnace, but offset to $100{ }^{\circ} \mathrm{C}$ lower temperature. This set of experiments clearly demonstrates the effect of microwaves for enhancing reaction kinetics. (3) Reactions of serpentine with alkaline carbonates and in acid solution were carried out in a microwave hydrothermal apparatus. There was a greatly enhanced decomposition of the serpentine in acid solution but, at the temperature and pressure of the reaction chamber $\left(15\right.$ bars; $\left.200{ }^{\circ} \mathrm{C}\right)$ the carbonates did not react. Overall, microwave fields, as expected, enhance silicate reaction kinetics, but higher $\mathrm{CO}_{2}$ pressures are needed to accomplish the desired sequestration reactions.
\end{abstract}




\section{TABLE OF CONTENTS}

1.0 INTRODUCTION

1.1 Objectives

1.2 Scope of Work

2.0 EXPERIMENTAL

2.1 Microwave Furnace

2.2 Microwave Hydrothermal Apparatus

3.0 RESULTS AND DISCUSSION

3.1 Direct Reaction of Serpentine and $\mathrm{CO}_{2}$

3.2 Serpentine Dehydroxylation

3.3 Microwave Hydrothermal Experiments

\subsection{CONCLUSIONS}

5.0 REFERENCES

6.0 APPENDIX: ACCELERATION OF SERPENTINE DEHYDROXYLATION KINETICS IN MICROWAVE FIELDS 


\subsection{INTRODUCTION}

\subsection{Objectives}

The proposed research concerns the sequestration of $\mathrm{CO}_{2}$ by reactions with the magnesium silicates to produce environmentally benign $\mathrm{MgCO}_{3}$.

$$
\begin{aligned}
& \mathrm{Mg}_{2} \mathrm{SiO}_{4}+2 \mathrm{CO}_{2} \rightarrow 2 \mathrm{MgCO}_{3}+\mathrm{SiO}_{2} \\
& \mathrm{Mg}_{3} \mathrm{Si}_{2} \mathrm{O}_{5}(\mathrm{OH})_{4}+3 \mathrm{CO}_{2} \rightarrow 3 \mathrm{MgCO}_{3}+2 \mathrm{SiO}_{2}+2 \mathrm{H}_{2} \mathrm{O}
\end{aligned}
$$

These reactions are thermodynamically favorable but suffer from exceeding slow reaction rates. Research by others has shown that reaction rates can be accelerated by use of aqueous carbonate solutions and high $\mathrm{CO}_{2}$ pressures. The proposed research offers an alternative rate enhancement mechanism through the use of microwave fields.

\subsection{Scope of Work and Task List}

The Scope of Work and list of tasks are taken directly from the original proposal. Progress and accomplishments on the tasks are then summarized in the sections that follow.

Two series of experiments were proposed. In series (1) a gas stream of $\mathrm{CO}_{2}$ containing variable amounts of water vapor would be reacted directly with the magnesium silicates at modest temperatures in a microwave cavity. The objective would be to determine the rate of reaction as a function of temperature, water vapor partial pressure, magnesium silicate particle size, and microwave power. In series (2) experiments, aqueous solutions would be reacted with $\mathrm{CO}_{2}$ under pressures up to 80 bars and temperatures up to $200 \mathrm{C}$ in a Teflon high pressure reactor in a microwave field. One objective of this portion of the research would be to compare the efficacy of microwave processing with similar compositions, temperatures and pressures without microwaves.

Task 1. Adapt existing microwave equipment for continuous gas stream reaction.

Task 2. React magnesium silicates with wet $\mathrm{CO}_{2}$ at a sequence of water contents, temperatures, and microwave power levels.

Task 3. Characterize products from Task 2 experiments and determine rates of reaction.

Task 4. Construct equipment for microwave hydrothermal experiments.

Task 5. React silicates in aqueous alkali carbonate solutions at autogeneous steam pressures in the microwave field.

Task 6. React silicates in aqueous alkali carbonate solutions at high $\mathrm{CO}_{2}$ pressures in the microwave field. 
Task 7. React silicates under similar conditions to Tasks 5 and 6 but in absence of microwave field

Task 8. Characterize results of experiments in Tasks 5, 6 and 7 and compare rates and reaction mechanisms.

\subsection{EXPERIMENTAL}

\subsection{Construction of Microwave Furnace}

The project was able to take advantage of the Center for Microwave Processing already in existence in the Materials Research Institute. The project was assigned use of an Amana Radrange commercial microwave furnace producing $2.0 \mathrm{~kW}$ of microwave energy at a frequency of $2.45 \mathrm{GHz}$. All that was required was to modify the furnace for use in the magnesium silicate/gas phase reactions.

A horizontal mullite tube was installed through the middle of the furnace (Fig. 1). The tube was insulated with Fiberfrax in the hot zone in the middle of the furnace. Samples were placed in alumina boats in the hot zone. Temperatures were measured with an infrared pyrometer which observed the sample through a window placed on the end of the mullite tube on the outside of the furnace. Fittings placed on the end of the mullite tube allowed selected gas mixtures to be passed through the furnace so that the

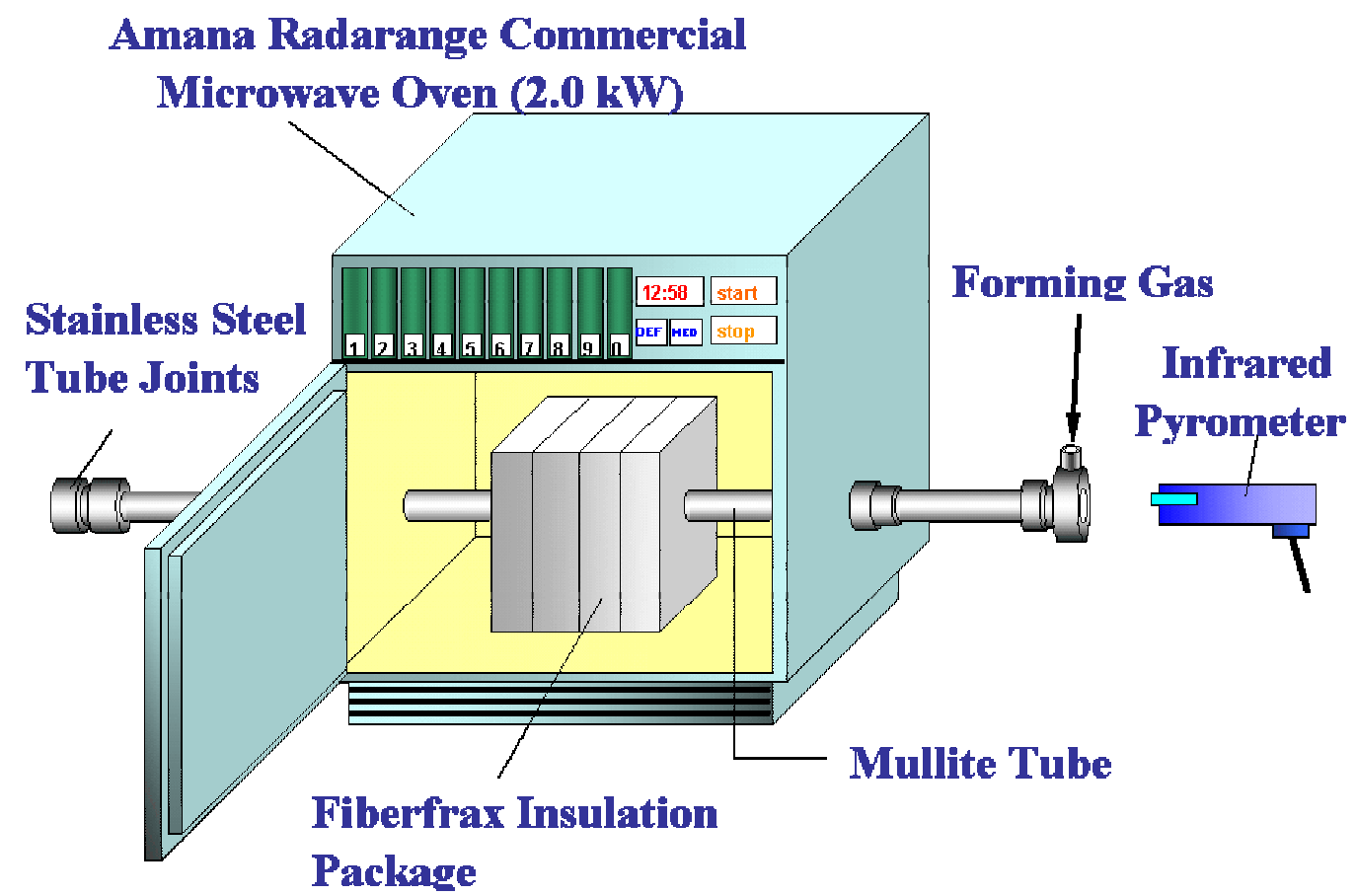

Figure 1. Drawing of microwave furnace. 
samples were continuously bathed in a gas atmosphere of known composition. This arrangement proved to be very effective and all of the solid/gas microwave experiments were performed with this equipment.

\subsection{Microwave Hydrothermal Apparatus}

The objective of this task was to devise an apparatus that would allow hydrothermal reactions in a microwave field. For this purpose we used a microwave digester such as used by analytical chemists for taking incalcitrant samples into solution. The pressure vessel is composed of Teflon. It will tolerate pressures to around 15 bars and temperatures to $200{ }^{\circ} \mathrm{C}$. The apparatus is shown in Figure 2.

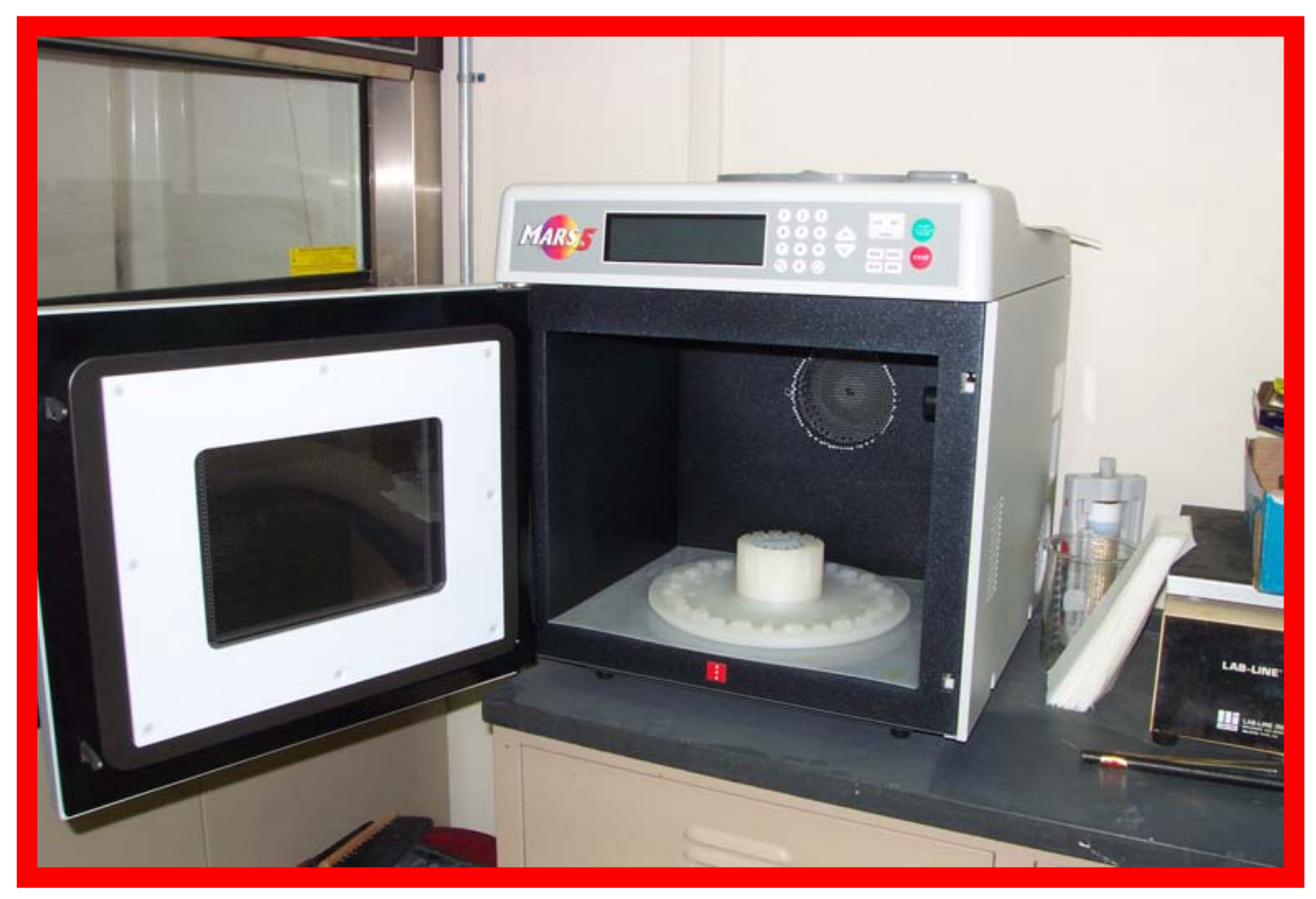

Figure 2. Microwave reaction chamber for hydrothermal experiments.

The Teflon pressure vessels are chemically resistant so that strongly basic or strongly acidic solutions can be reacted. The temperature is measured directly within the chamber but the pressure must be calculated from the known thermodynamic properties of water. Pressure can be varied by varying the volume of solution placed in the reaction vessel. The pressure vessel is shown in Fig. 3 


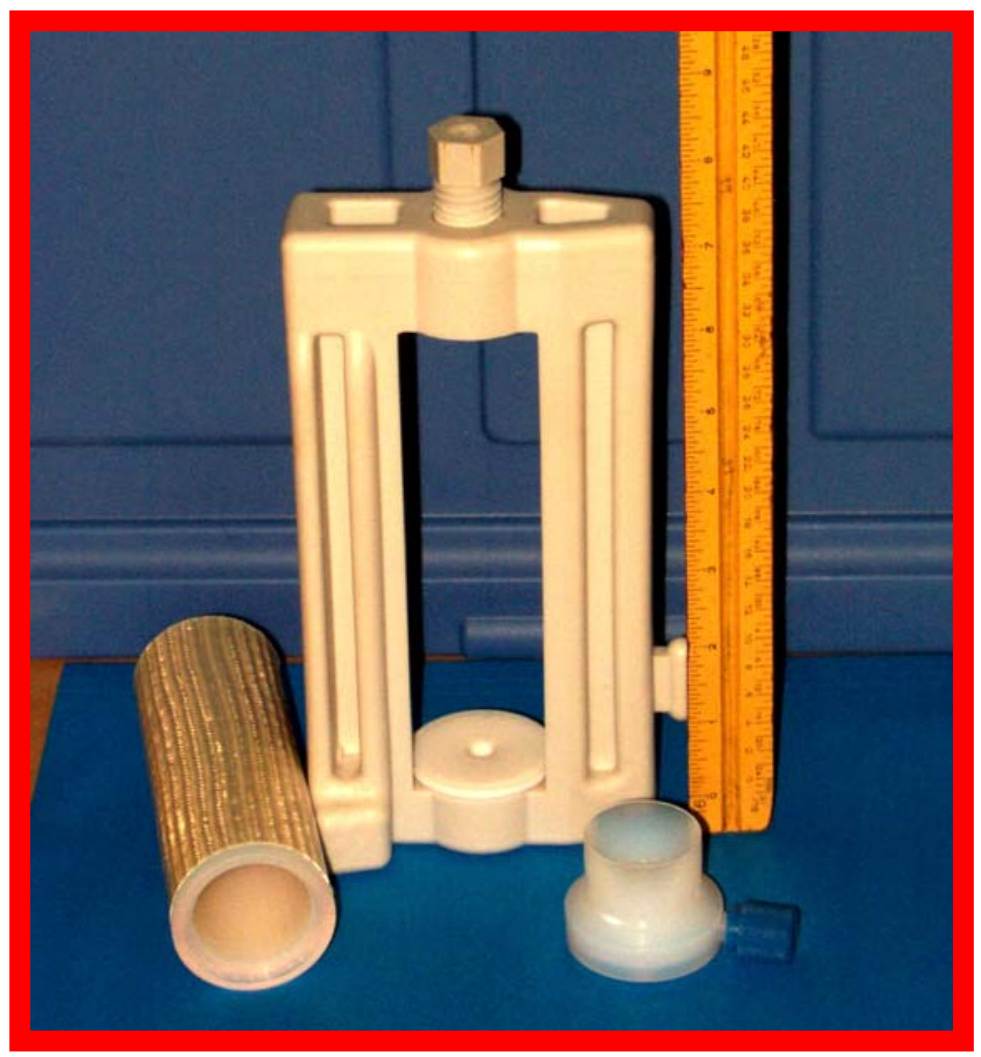

Figure 3. Teflon microwave hydrothermal pressure vessel is disassembled form.

\subsection{RESULTS AND DISCUSSION}

\subsection{Direct Reaction of Serpentine and $\mathrm{CO}_{2}$}

The main thrust of the investigation was the direct reaction of serpentine with $\mathrm{CO}_{2}$ in the microwave furnace. Three different serpentines were available referred to by their sources as Welch, Wards, and Cedar Hill. Their mineralogy is listed in Table 1.The Welch serpentine was mostly used in the direct carbonation experiments.

The carbonation reaction

$$
\mathrm{Mg}_{3} \mathrm{Si}_{2} \mathrm{O}_{5}(\mathrm{OH})_{4}+3 \mathrm{CO}_{2} \rightarrow 3 \mathrm{MgCO}_{3}+2 \mathrm{SiO}_{2}+2 \mathrm{H}_{2} \mathrm{O}
$$

Depends on both the $\mathrm{CO}_{2}$ partial pressure and water vapor pressure as well as the temperature. The equilibrium constant for the reaction is 


$$
\frac{P_{\mathrm{H}_{2} \mathrm{O}}^{2}}{P_{\mathrm{CO}_{2}}^{3}}=K_{\text {serp }}
$$

Table 1. Properties of Serpentine Starting Materials

\begin{tabular}{ll}
\hline Sample & Mineralogy \\
\hline Welsh & Lizardite + minor dolomite \\
Wards & Chrysotile + minor \\
& antigorite \\
Cedar Hill & Lizardite + minor antigorite \\
\hline
\end{tabular}

It is also necessary to consider the stability of magnesite because at high temperatures magnesite will decompose into periclase $(\mathrm{MgO})$ and release the $\mathrm{CO}_{2}$. The reaction is

$$
\mathrm{MgCO}_{3} \rightarrow \mathrm{MgO}+\mathrm{CO}_{2}
$$

This reaction also depends on both temperature and $\mathrm{CO}_{2}$ pressure.

$$
P_{\mathrm{CO}_{2}}=K_{m a g}
$$

Equilibrium constants for both reactions were calculated from available thermodynamic data (R.A. Robie and B.S. Hemingway, 1995). These allowed the plotting of univariant reaction curves for both reactions (Fig. 4).

The univariant reaction curve for the carbonation reaction was calculated using a fixed partial pressure of water of 0.029 bars, the saturation vapor pressure of water at ambient temperatures. These curve define a minimum $\mathrm{CO}_{2}$ pressure and a maximum temperature at which the carbonation reaction can take place.

Half gram quantities of serpentine were reacted in the microwave furnace in an atmosphere of $\mathrm{CO}_{2}$ gas that has been saturated with water vapor at various temperatures over the range of 375 to $650{ }^{\circ} \mathrm{C}$. Reaction products were characterized by $\mathrm{x}$-ray diffraction and by infrared spectroscopy. Although traces of carbonate minerals were discernable in the x-ray diffraction patterns, it was entirely possible that these represented traces of carbonate minerals present in the original serpentine samples. 


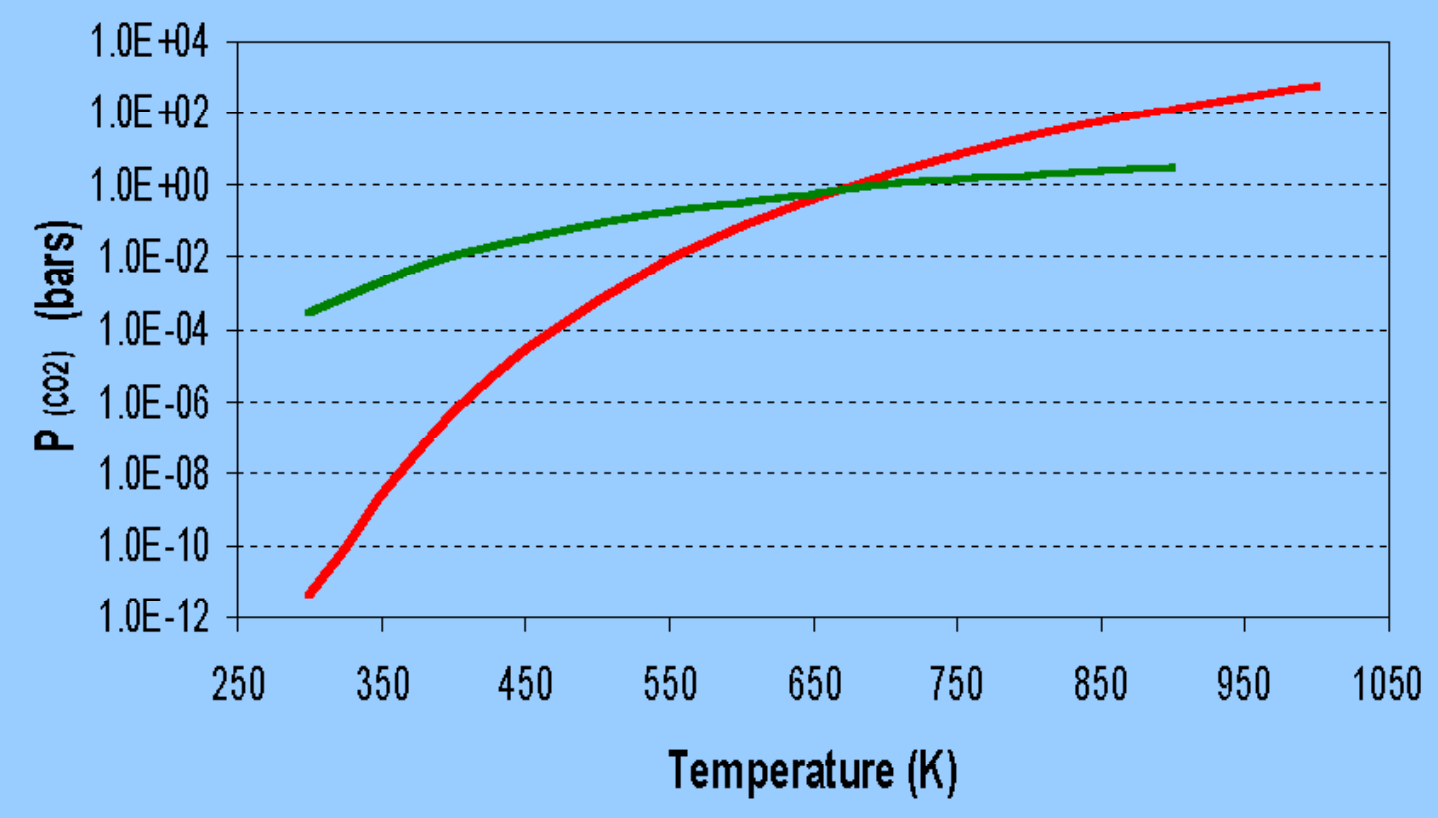

Figure 4. Univariant reaction curves for the carbonation of serpentine (green curve) and the decomposition of magnesite (red curve).

The furnace design allowed only atmospheric pressure for the gases. Given the limitations set by the thermodynamics, it was not possible to raise the temperature high enough to drive the carbonation reaction. It would be necessary to conduct microwave enhanced reactions at higher pressures.

\subsection{Dehydroxylation of Serpentine}

The influence of the microwave field was most pronounced in the dehydroxylation of serpentine. At somewhat higher temperatures than those involved in the carbonation reactions, serpentine breaks down into forsterite, $\mathrm{Mg}_{2} \mathrm{SiO}_{4}$ and silica. The reaction is

$$
2 \mathrm{Mg}_{3} \mathrm{Si}_{2} \mathrm{O}_{5}(\mathrm{OH})_{4} \rightarrow 3 \mathrm{Mg}_{2} \mathrm{SiO}_{4}+\mathrm{SiO}_{2}+4 \mathrm{H}_{2} \mathrm{O}
$$

There was a certain temperature required for the onset of the reaction. As the temperature increased, the reaction proceeded rapidly to completion. At a fixed time of 30 minutes, the fraction of serpentine (or olivine formed) was described by a characteristic S-shaped (or Avrami) type kinetics curve (Fig. 5). The kinetics curve for the reaction in the microwave furnace was compared with the dehydroxylation reaction for serpentine in a conventional resistance-heated furnace. The reaction curves were 


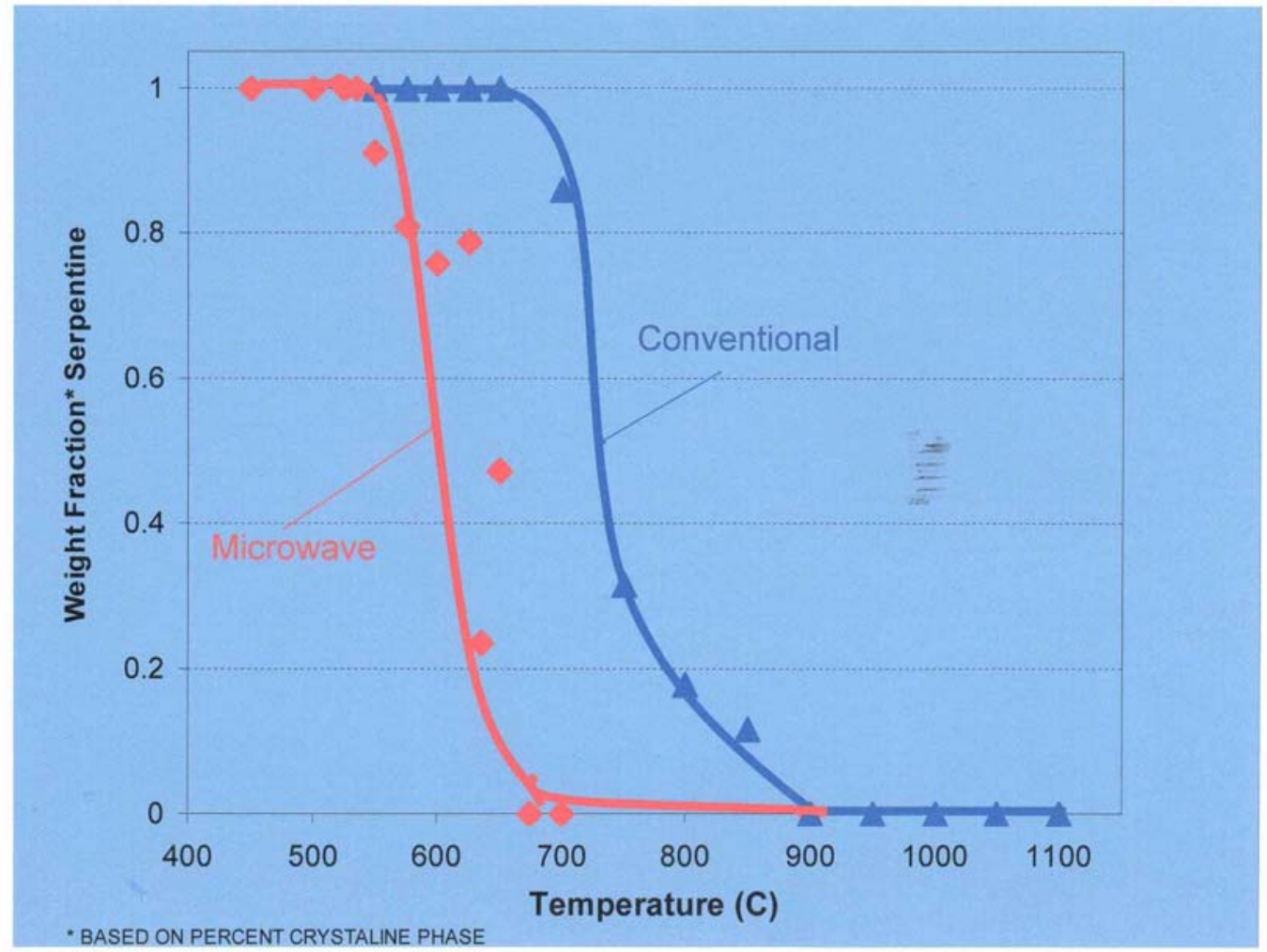

Figure 5. Rate curves for the dehydroxylation of serpentine comparing microwaveassisted reaction with reaction in conventional resistance-heated furnace

similar but the microwave-assisted kinetics curve was offset about $100{ }^{\circ} \mathrm{C}$ to lower temperature. As found in many other experiments, microwave assisted reactions tend to be faster and/or require less thermal activation that the same reaction by thermal activation alone.

This set of experiments was followed up in considerable detail and the results prepared for publication. The manuscript is attached as an appendix to this report. Completed references comparing these experiments with previous research is also given in the appendix.

\subsection{Microwave Hydrothermal Experiments}

The microwave digester described above was used in two series of experiments to investigate the reaction of serpentine with a variety of fluids. The Teflon reaction vessel allows a great range of solutions but limits pressure and temperature to about 15 atmospheres and $200{ }^{\circ} \mathrm{C}$ 
In the first series of experiments Cedar Hill serpentine was reacted with alkali carbonates:

$$
\begin{aligned}
& \text { Serpentine + } 1 \mathrm{M} \mathrm{Na}_{2} \mathrm{CO}_{3} \\
& \text { Serpentine }+1 \mathrm{M} \mathrm{NaHCO}_{3} \\
& \text { Serpentine }+1 \mathrm{M} \mathrm{NaOH}+0.64 \mathrm{M} \mathrm{NaHCO}_{3} \\
& \text { Serpentine }+1 \mathrm{M} \mathrm{NaCl}+0.64 \mathrm{NaHCO}_{3}
\end{aligned}
$$

These mixtures were reacted for various periods of time and the products examined for the formation of carbonate minerals. In these alkaline solutions no reaction products were found.

In the second series of experiments, serpentine was reacted with low $\mathrm{pH}$ solutions achieved with $\mathrm{HCl}$. Digestion of the serpentine was extensive with some formation of forsterite, $\mathrm{Mg}_{2} \mathrm{SiO}_{4}$, but with an amorphous mass as the bulk of the reaction product. There was extensive extraction of magnesium into solution but relatively little silica (Fig. 6)

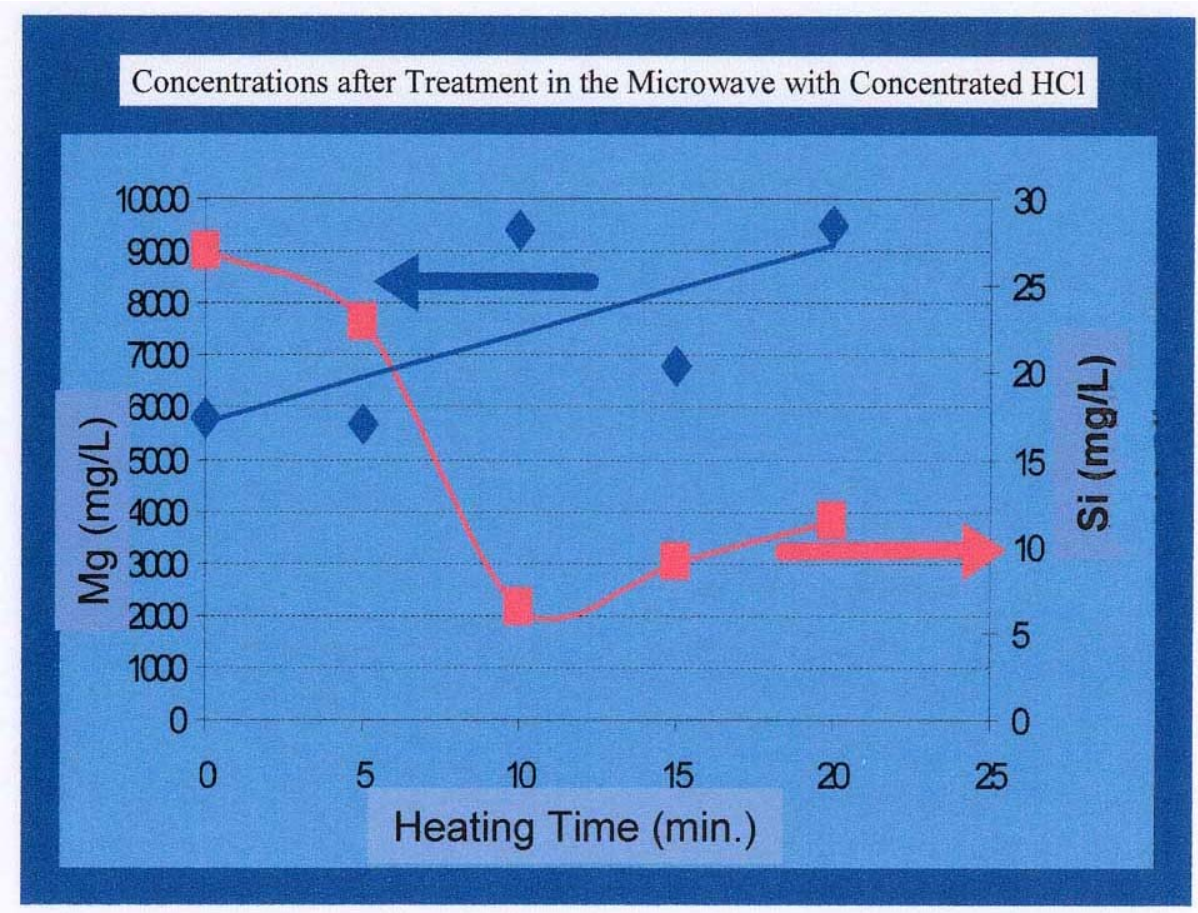

Figure 6. Uptake of magnesium and silicon following microwave hydrothermal digestion of serpentine in low $\mathrm{pH}$ solution. 
Like the direct carbonation experiments, microwave hydrothermal experiments enhance reaction rates. However, it appears that higher $\mathrm{CO}_{2}$ pressures will be necessary for useful carbonation reactions to proceed.

\subsection{CONCLUSIONS}

Overall, the exploratory study to investigate the role of microwave enhancement of silicate reaction rates reduces to two main conclusions:

(1) Reaction rates in microwave fields are substantially faster or alternatively react at lower temperatures than the same reactions driven by conventional thermal heating.. It was convenient to measure rates at variable temperature and constant time with the result that serpentine dehydroxylation occurred about $100{ }^{\circ} \mathrm{C}$ lower than thermally driven reactions.

(2) Given the univariant reaction curve between serpentine and $\mathrm{CO}_{2}$ to form magnesite, it appears that future experimentation will require $\mathrm{CO}_{2}$ pressures higher than those accessible in the present experiments. A high pressure microwave hydrothermal could be designed.

\subsection{REFERENCES}

Robie, R.A. and B.S. Hemingway (1995) Thermodynamic properties of minerals and related substances at $298.15 \mathrm{~K}$ and $1 \mathrm{bar}\left(10^{5}\right.$ Pascals $)$ pressure and at higher temperatures. U.S. Geological Survey Bull. 2131. 


\title{
Appendix \\ ACCELERATION OF SERPENTINE DEHYDROXYLATION KINETICS IN MICROWAVE FIELDS
}

\author{
Michael R. Silsbee, B. Joe Kearns and William B. White
}

Manuscript prepared for submission to the Journal of the American Ceramic Society 


\title{
Acceleration of Serpentine Dehydroxylation Kinetics in
}

\section{Microwave Fields}

\author{
Michael R. Silsbee*, B. Joe Kearns and William B. White* \\ Materials Research Institute, The Pennsylvania State University, University Park, PA \\ 16802
}

As part of a study of the use of microwave enhancement of reaction kinetics for sequestration of $\mathrm{CO}_{2}$ by reaction with serpentine, the kinetics of the dehydroxylation reaction of serpentine was determined. The reaction is

$$
2 \mathrm{Mg}_{3} \mathrm{Si}_{2} \mathrm{O}_{5}(\mathrm{OH})_{4} \rightarrow 3 \mathrm{Mg}_{2} \mathrm{SiO}_{4}+\mathrm{SiO}_{2}+4 \mathrm{H}_{2} \mathrm{O}
$$

X-ray diffraction patterns revealed the disappearance of serpentine as the reactions proceeded and the appearance of forsterite, $\mathrm{Mg}_{2} \mathrm{SiO}_{4}$, as the only crystalline phase. However, quantitative X-ray diffraction suggests that up to $90 \%$ of the reaction product is non-crystalline. The rate curve for this reaction exhibits a characteristic S-shape or Avrami form. Comparison with the rate curve obtained by conventional thermal reaction shows that the microwave assisted reaction occurs about $100{ }^{\circ} \mathrm{C}$ lower.

Research supported of the U.S. Department of Energy under Award No. DE-FG2602NT41545. However, any opinions, findings, conclusions or recommendations expressed herein are those of the authors and do not necessarily reflect the views of the DOE.

*Member, American Ceramic Society

Author to whom correspondence should be addressed. E-mail: wbw2@psu.edu 


\section{Introduction}

Substantial efforts are being made to devise technologies for the reduction of greenhouse gases in the atmosphere ${ }^{1}$. One of the more environmentally desirable technologies for the sequestration of $\mathrm{CO}_{2}$ is the reaction of $\mathrm{CO}_{2}$ in stack gases with serpentine, forsterite and related ultramafic minerals to immobilize the $\mathrm{CO}_{2}$ as the benign compound magnesite ${ }^{2-4}$. The reaction for serpentine is

$$
\mathrm{Mg}_{3} \mathrm{Si}_{2} \mathrm{O}_{5}(\mathrm{OH})_{4}+3 \mathrm{CO}_{2} \rightarrow 3 \mathrm{MgCO}_{3}+2 \mathrm{SiO}_{2} 2 \mathrm{H}_{2} \mathrm{O}
$$

The thermodynamics of the forward reaction are favorable up to $427 \mathrm{C}$ for a $\mathrm{CO}_{2}$ pressure of one atmosphere and to higher temperatures at higher $\mathrm{CO}_{2}$ pressures. However, the reaction rate of the gas/solid reaction is extremely sluggish at all temperatures below the thermodynamic phase boundary. To circumvent the slow reaction rates, a variety of high pressure reaction chambers using solvents have been devised $^{5-7}$

The research reported in this paper deals with the question of whether microwave fields enhance reaction rates when applied to silicate reactions. Microwave processing has been widely applied to enhance sintering and other ceramic reactions and there have been some considerations of mineral processing ${ }^{8,9}$. Whether the acceleration of ceramic reactions is simply the result of more effective heat transfer or whether there are effects of the microwave field itself remains an open question. Recent experiments with ferrites suggest that there is more to microwave reactions than heat $\operatorname{transfer}^{10-12}$.

In the present paper we report the results of a series of experiments on the dehydroxylation of serpentine in which we compare the reaction kinetics in a microwave field with kinetics under conventional heating. The reaction is 


$$
2 \mathrm{Mg}_{3} \mathrm{Si}_{2} \mathrm{O}_{5}(\mathrm{OH})_{4} \rightarrow 3 \mathrm{Mg}_{2} \mathrm{SiO}_{4}+\mathrm{SiO}_{2}+4 \mathrm{H}_{2} \mathrm{O}
$$

The reaction products are forsterite, which appears in a well-crystallized form easily recognized by its $x$-ray powder pattern, and silica which does not appear crystalline. The equilibrium constant for the reaction is

$$
K=P_{H_{2} O}^{4}
$$

Values for $\mathrm{K}$ at various temperatures were calculated from the thermochemical data of Robie and Hemingway ${ }^{13}$ using both quartz $\left(\mathrm{K}=1.039 \times 10^{-23}\right.$ at $\left.300 \mathrm{~K}\right)$ and silica glass $\left(\mathrm{K}=6.536 \times 10^{-25}\right.$ at $\left.300 \mathrm{~K}\right)$ as the silica phase. The univariant reaction curves are very similar (Fig. 1). The minimum temperature at which the reaction should proceed depends on the water vapor partial pressure as indicated on figure 1.

\section{Experimental Methods}

\section{(1) Starting Materials}

Samples of serpentine were obtained from three sources. Each was characterized by X-ray diffraction (Table 1). The starting materials were ground to a particle size in the range of $20-100 \mu \mathrm{m}$. The dehydration characteristics of the starting materials were checked by thermogravimetric analysis. The dehydration curves are similar but not identical (Fig. 2).

\section{(2) Furnaces}

The microwave furnace was a commercial device (Amana Radarange) producing $2.0 \mathrm{~kW}$ of microwave energy at $2.45 \mathrm{GHz}$. A horizontal mullite tube was installed through the middle of the furnace (Fig.3). The tube was insulated with Fiberfrax in the hot zone in the middle of the furnace. Samples were placed in alumina boats in the hot zone. Temperatures were measured with an infrared pyrometer which observed the 
sample through a window placed on the end of the mullite tube on the outside of the furnace. A gas atmosphere consisting of $\mathrm{H}_{2} \mathrm{O}$-saturated $\mathrm{CO}_{2}$ was passed through the furnace during the experiments. This gives a water vapor partial pressure of approximately $2.5 \mathrm{kPa}$.

For conventional firing, a resistance-heated furnace was used. It also contained a horizontal mullite tube. Temperatures were determined with a thermocouple placed near the samples. The furnace atmosphere was also water-saturated $\mathrm{CO}_{2}$.

\section{(3) Experimental Procedures}

About 0.5 grams of powdered serpentine were placed in alumina boats which were in turn placed in the hot zone of either the microwave or the resistance furnace. Power was applied to the microwave system and the temperature tracked by the optical pyrometer. When the sample reached the desired temperature, the temperature was held constant for the prescribed time after which the power was shut off and the furnace allowed to cool. Samples were not quenched. Figure 4 shows a typical firing cycle. Firing in the resistance-heated furnace followed similar procedures.

After reaction, the samples were characterized by x-ray powder diffraction and by scanning electron microscopy. The intensities of the $100(\mathrm{~d}=7.300 \AA$ Á) reflection of serpentine and the $020(\mathrm{~d}=5.102 \AA$ ) reflection of olivine were used for quantitative analysis of the progress of the reaction. The reaction products were packed into hollow slides, and measured carefully for quantitative line intensities. The x-ray peak intensities of the reaction products were compared with the peak intensities of end-member serpentine and end-member olivine to determine the progress of the reactions. 


\section{Results}

\section{(1) Characterization}

The progress of reaction was tracked by changes in the x-ray diffraction patterns (Fig.5). The patterns shown in figure 5 were all obtained on material that had been reacted in the microwave field for 30 minutes at the temperatures shown. The characteristic powder pattern of serpentine persists up to $535^{\circ} \mathrm{C}$. At higher temperatures, the serpentine pattern is replaced by the pattern of olivine. There is no evidence for crystalline intermediate phases in the diffraction patterns. The silica component in the dehydroxylation reaction does not appear as a crystalline phase. Further, considerations of the quantitative intensities of the diffraction peaks suggests that olivine can account for only $10-20$ percent of the reaction product. The remainder must be present in noncrystalline form.

A comparison of the microstructures resulting from the dehydroxylation reaction is shown in figures 6 and 7. The same crushed Ward's serpentine was used as a starting material. The intent was to compare the structures at the same location on the dehydroxylation curve so the microwave processed samples were prepared at $600{ }^{\circ} \mathrm{C}$, the beginning of the reaction, at $650{ }^{\circ} \mathrm{C}$, about the mid-point in the reaction, and at $700{ }^{\circ} \mathrm{C}$, near the end of the reaction. To get a comparable sequence of images for serpentine dehydroxylated by conventional heating, the images were obtained from materials heated at 700,750 and $800{ }^{\circ} \mathrm{C}$ respectively.

The microwave-reacted material retains much of its original texture in spite of the rearrangement of the mineralogy. In contrast, the conventionally heated material shows considerable grain growth. The material completely reacted by microwave was 
considerably more compact that the corresponding material reacted by conventional firing.

The BET surface areas were compared for materials prepared by the two reaction techniques (Table 2). The surface areas of the microwave-reacted materials are smaller than those of materials prepared by ordinary firing.

\section{(2) Kinetics}

The relative rates of reaction can be compared either as a function of time at constant temperature or as a function of temperature at constant time. For both approaches, the technique was to compare intensities of selected x-ray peaks and normalize these to a fraction of serpentine in the sample.

Remaining serpentine as a function of time at $650{ }^{\circ} \mathrm{C}$ shows a pronounced contrast between microwave heating and conventional heating (Fig. 8). After 60 minutes in the conventional furnace at $650{ }^{\circ} \mathrm{C}$, only a few percent of the serpentine had dehydrated. At the same temperature in the microwave furnace, most of the serpentine had lost its hydroxyl groups after only 15 minutes and at 60 minutes all serpentine had been dehydroxylated.

Reaction rates were compared at a fixed time of 30 minutes (Fig. 9). Both methods of heating produced the expected S-shaped or Avrami type rate curve. However, the curve for conventional heating is offset by about 100 degrees from the microwave heating curve. Both curves show an abrupt onset of dehydroxylation with reaction going to completion over a relatively narrow temperature range.

An obvious consideration is whether the difference in rate curves arises simply from lag in heat flow. The microwave samples would be heated uniformly through the 
mass of the powder so that temperature rise would be rapid and the dehydroxylation reaction begin immediately throughout the mass of the sample. Because heat flow in the conventional furnace is from the outside of the sample and the powdered silicate is a good thermal insulator, one might expect the temperature rise in the central portions of the sample to lag and thus the effective reaction time at temperature would be shorter. As one test this possibility, a thermocouple was buried in the center of the mass of powder so that the temperature at the core of the sample could be monitored directly. It was found that, for the size of samples used in this investigation, there is a lag of about 10 minutes before the core of the sample came to full reaction temperature. It was not possible to make a similar measurement in the microwave chamber. As a second test, the reactions were carried out with $0.1,0.2,0.5$, and 1.0 grams of powder. The reaction rates were essentially the same and independent of the amount of material in the furnace. Overall, it does not seem that the offset between the two reaction curves are primarily an experimental artifact.

\section{Conclusions}

A comparison of the reaction rates for the dehydroxylation of serpentine between microwave driven reaction and ordinary furnace heating shows that the microwave driven reaction is substantially faster. Both techniques give the expected S-shaped reaction curve but in the microwave driven system the mid-point of the reaction curve is shifted to lower temperatures by about $100{ }^{\circ} \mathrm{C}$. The microwave reacted product is of smaller particle size but has a lower surface area then the material prepared by conventional firing.. It appears that microwave processing might be a useful approach to preparing precursor materials for carbon sequestration reactions. 


\section{Acknowledgements}

We thank David Dahlen of the Albany Research Center for providing the Cedar Hill serpentine.

\section{References}

${ }^{1}$ K.S. Lackner, “A Guide to $\mathrm{CO}_{2}$ Sequestration,” Science, 300, 1677-1678 (2003).

${ }^{2}$ W. Seifritz, “CO $\mathrm{CO}_{2}$ Disposal by Means of Silicates,” Nature, 345, 486 (1990).

${ }^{3}$ K.S. Lackner, C.H. Wendt, D.P. Butt, E.L. Joyce, and D.P. Sharp, “Carbon Dioxide Disposal in Carbonate Minerals," Energy, 20, 1153-1170 (1995).

${ }^{4}$ F. Goff and K.S. Lackner, "Carbon Dioxide Sequestering Usisng Ultramafic Rocks," Environ. Geosci. 5, 89-101.

${ }^{5}$ W.K. O’Connor, D.C. Dahlin, D.N. Nilsen, G.E. Rush, R.P. Walters, and P.C. Turner, “Carbon Dioxide Sequestration by Direct Mineral Carbonation: Results from Recent Studies and Current Status," Proc. First Natl. Conf. Carbon Sequestration, Washington, DC (2001).

${ }^{6}$ M.J. McKelvy, A.V.G. Chizmeshya, H. Bearat, R. Sharma and R.W. Carpenter, "Developing a Mechanistic Understanding of Lamellar Hydroxide Mineral Carbonation Reaction Processes to Reduce $\mathrm{CO}_{2}$ Mineral Sequestration Process Cost," Proc. First Natl. Conf. Carbon Sequestration, Washington, DC (2001).

${ }^{7}$ G.D. Guthrie, Jr., J.W. Carey, D. Bergfeld, D. Byler, S. Chipera, H.-J. Ziock and K. Lackner," Geochemical Aspects of the Carbonation of Magnesium Silicates in an 
Aqueous Medium," Proc. First Natl. Conf. Carbon Sequestration, Washington, DC (2001).

${ }^{8}$ S.W. Kingman and N.A. Rowson, "Microwave Treatment of Minerals - A Review," Mineral. Eng., 11, 1081-1087 (1998).

${ }^{9}$ K.E. Haque, "Microwave Energy for Mineral Treatment Processes - A Brief Review," Internat. J. Mineral. Process. 57, 1-24 (1999).

${ }^{10}$ R. Roy, P.D Peelamedu, L. Hurtt, J.P. Cheng, and D. Agrawal, "Definitive Experimental Evidence for Microwave Effects: Radically New Effects of Separated E and H Fields, such as Decrystallization of Oxides in Seconds,", Mat. Res. Innovat., 6, 128-140 (2002).

${ }^{11}$ J. Cheng, D. Agrawal, Y. Zhang and R. Roy, "Development of Translucent Aluminum Nitride (AlN) Using Microwave Sintering Process," J. Electroceramics, 9, 6771 (2002).

${ }^{12}$ R. Roy, P.D. Peelamedu, J.P. Cheng, C. Grimes and D. Agrawal, "Major Phase Transformations and Magnetic Property Changes Caused by Electromagnetic Fields at Microwave Frequencies," J. Mater. Res. 17, 3008-3011 (2002).

${ }^{13}$ R.A. Robie and B.S. Hemingway, "Thermodynamic Properties of Minerals and Related Substances at $298.15 \mathrm{~K}$ and 1 bar $\left(10^{5}\right.$ Pascals $)$ Pressure and at Higher Temperatures," U.S. Geol. Survey Bull. 2131, 461 p (1995). 
Table I. Properties of Serpentine Starting Materials

\begin{tabular}{ll}
\hline Sample & Mineralogy \\
\hline Welsh & Lizardite + minor dolomite \\
Wards & Chrysotile + minor \\
& antigorite \\
Cedar Hill & Lizardite + minor antigorite \\
\hline
\end{tabular}

Table II. BET Surface Areas After Processing (in units of $\mathrm{m}^{2} / \mathrm{gram}$ )

\begin{tabular}{l|ll} 
Temperature $(\mathbf{C})$ & Conventional & Microwave \\
\hline $\mathbf{6 0 0}$ & & 2.45 \\
$\mathbf{6 5 0}$ & 4.19 & 3.03 \\
$\mathbf{7 0 0}$ & 2.37 & 0.37 \\
$\mathbf{7 5 0}$ & 6.95 & \\
$\mathbf{8 0 0}$ &
\end{tabular}




\section{Legends for Figures}

Fig. 1 Univariant phase boundary for the reaction $2 \mathrm{Mg}_{3} \mathrm{Si}_{2} \mathrm{O}_{5}(\mathrm{OH})_{4} \rightarrow 3 \mathrm{Mg}_{2} \mathrm{SiO}_{4}+$ $\mathrm{SiO}_{2}+4 \mathrm{H}_{2} \mathrm{O}$ as a function of water vapor partial pressure. Calculations with two choices of $\mathrm{SiO}_{2}$ phase are shown.

Fig. 2. Thermogravimetric curves for the three samples of serpentine used in the dehydroxylation experiments.

Fig. 3 Schematic drawing of the microwave furnace.

Fig. 4 Time-temperature profile for microwave heating chamber.

Fig. 5 Sequence of $x$-ray diffraction patterns for 30 minute dehydroxylation of serpentine at various temperatures in a microwave field.

Fig. 6 SEM images of Ward's serpentine after firing in a microwave field for 30 minutes at the temperatures indicated.

Fig. 7 SEM images of Ward's serpentine after firing in a resistance furnace for 30 minutes at the temperature indicated.

Fig. 8 Rate curves for the dehydroxylation of serpentine at $650{ }^{\circ} \mathrm{C}$ in a conventional resistance furnace and in a microwave furnace.

Fig. 9 Rate curves for the dehydroxylation as a function of temperature at a constant time of 30 minutes. 


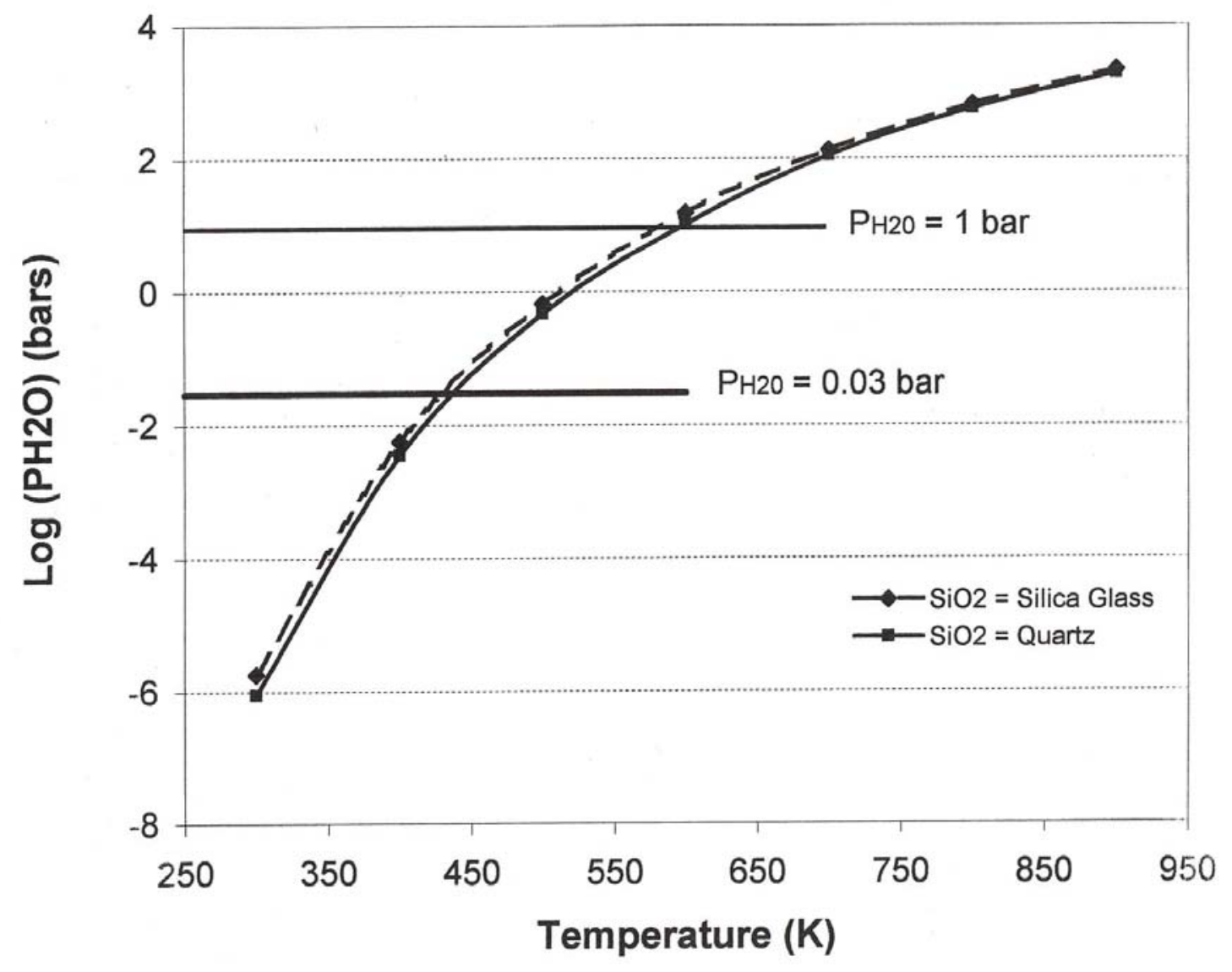




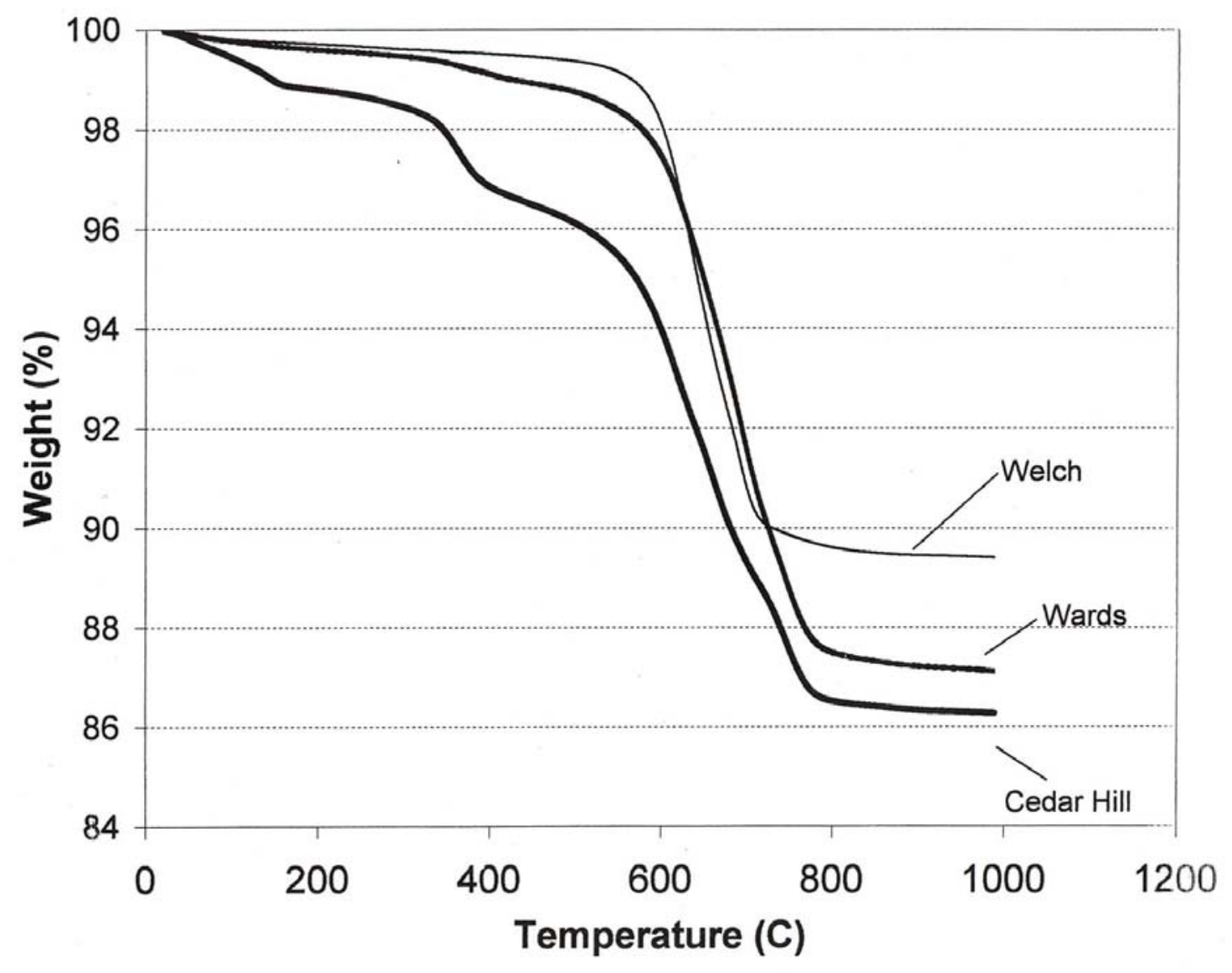


MICROWAVE PROCESSING AND ENGINEERING CENTER

\section{Scheme of the Tube Microwave Processing Setup}
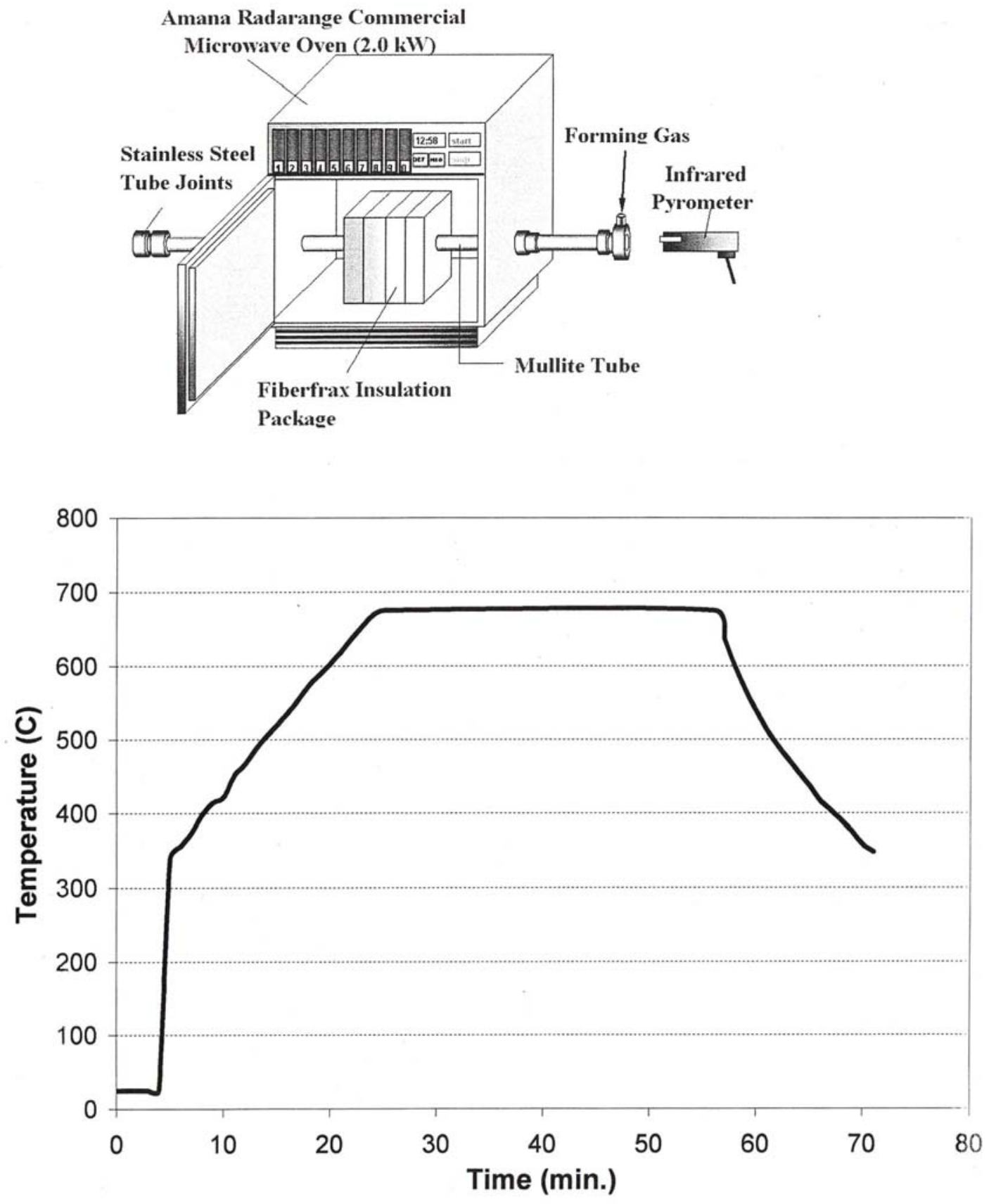


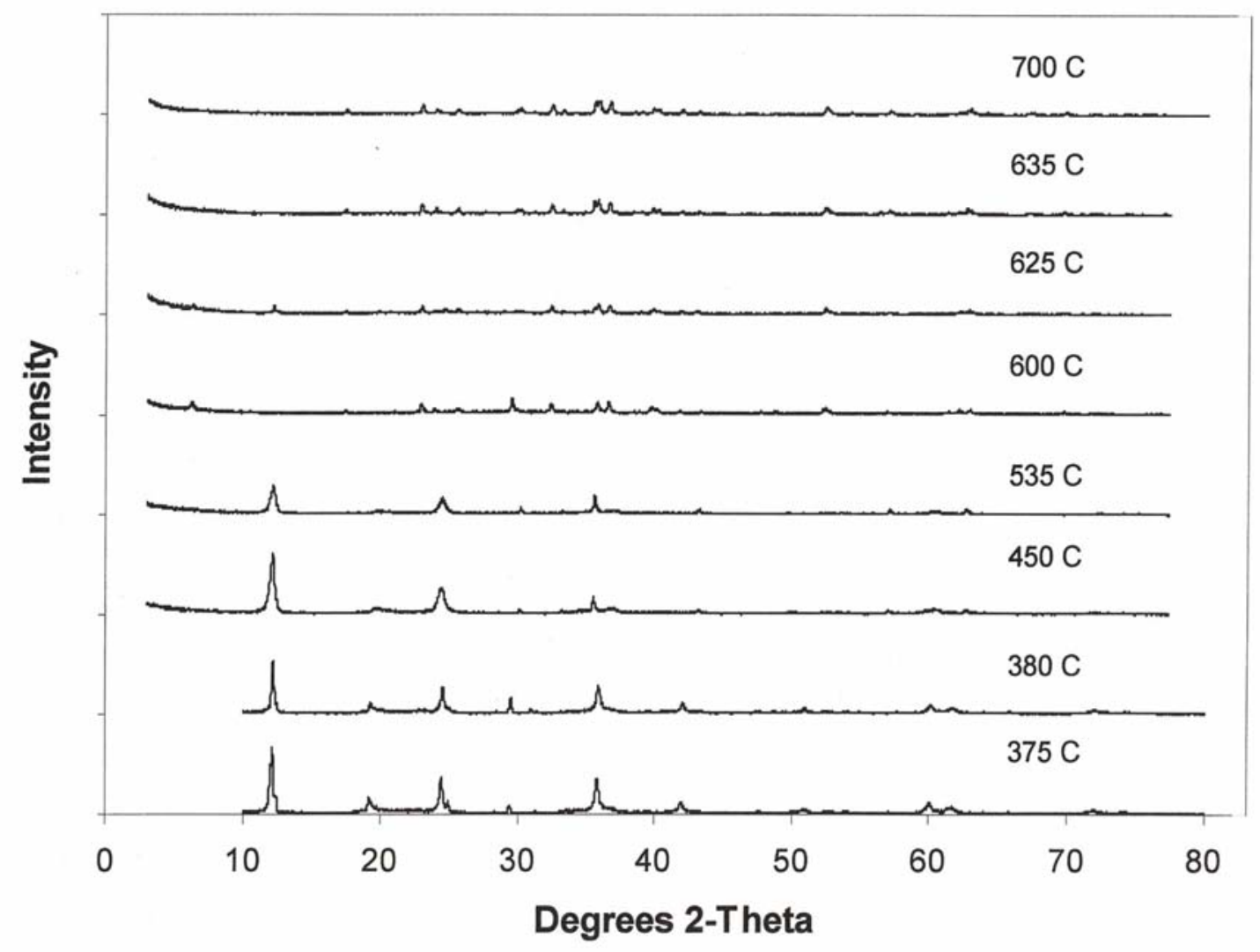




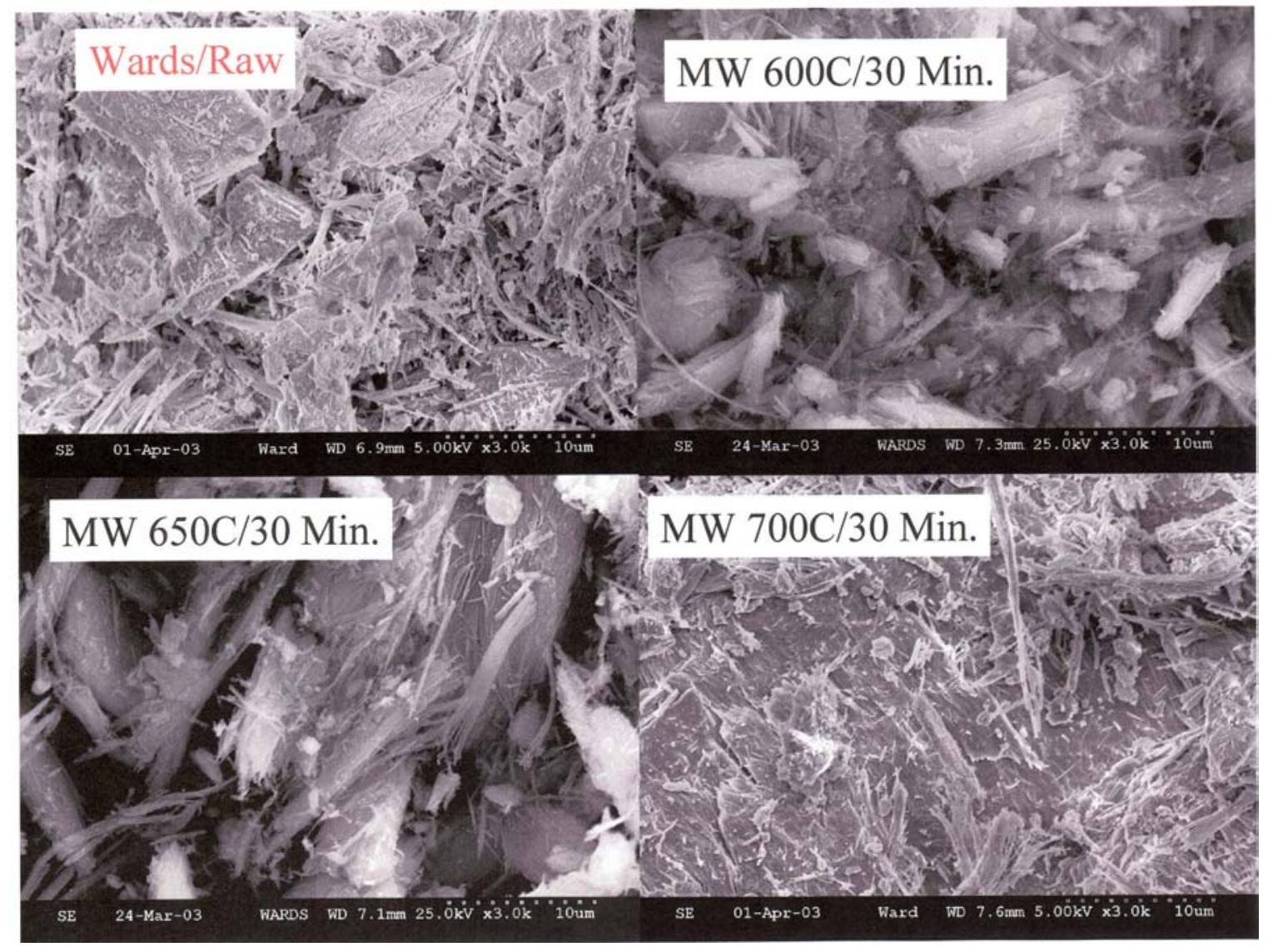



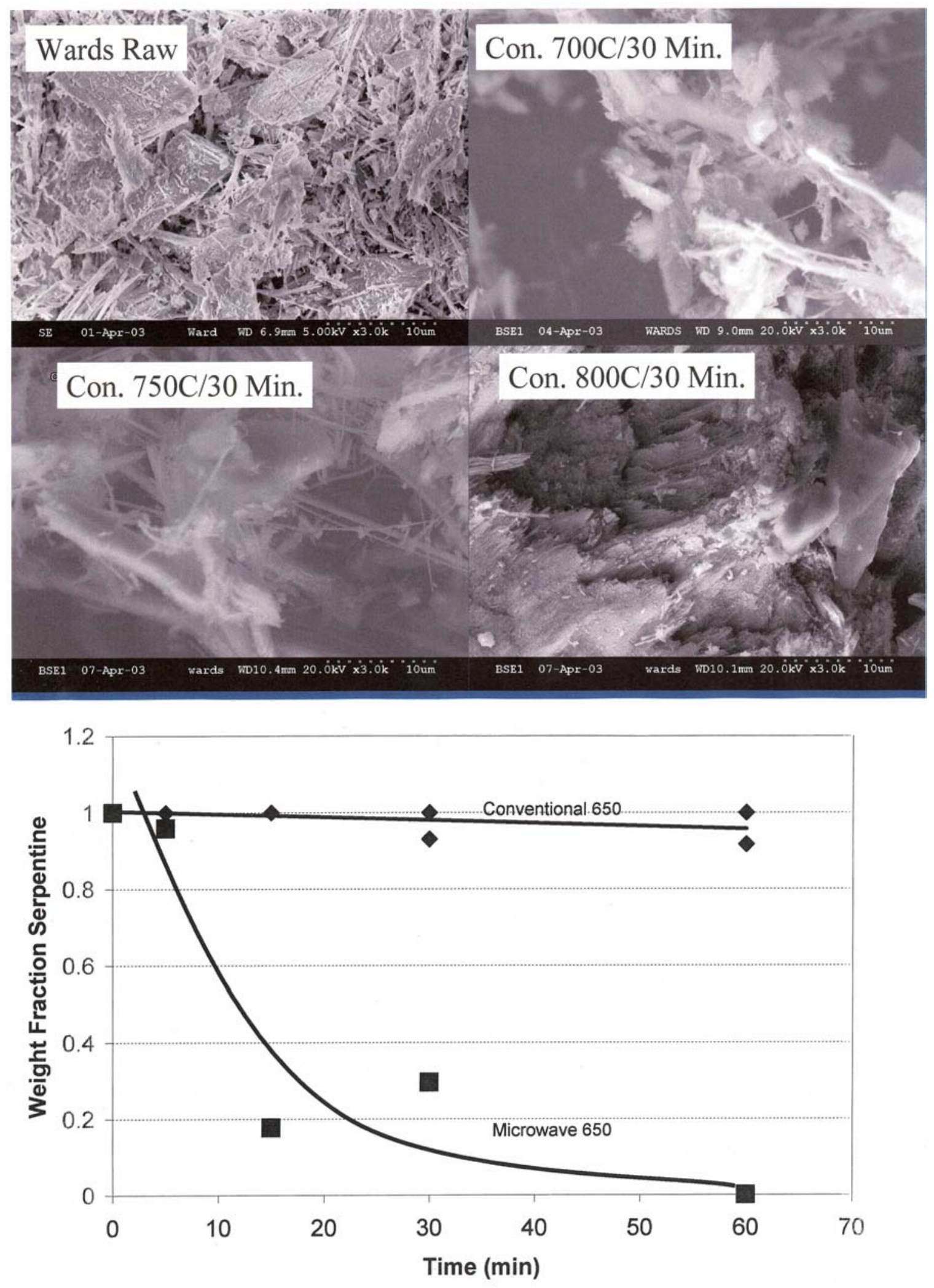


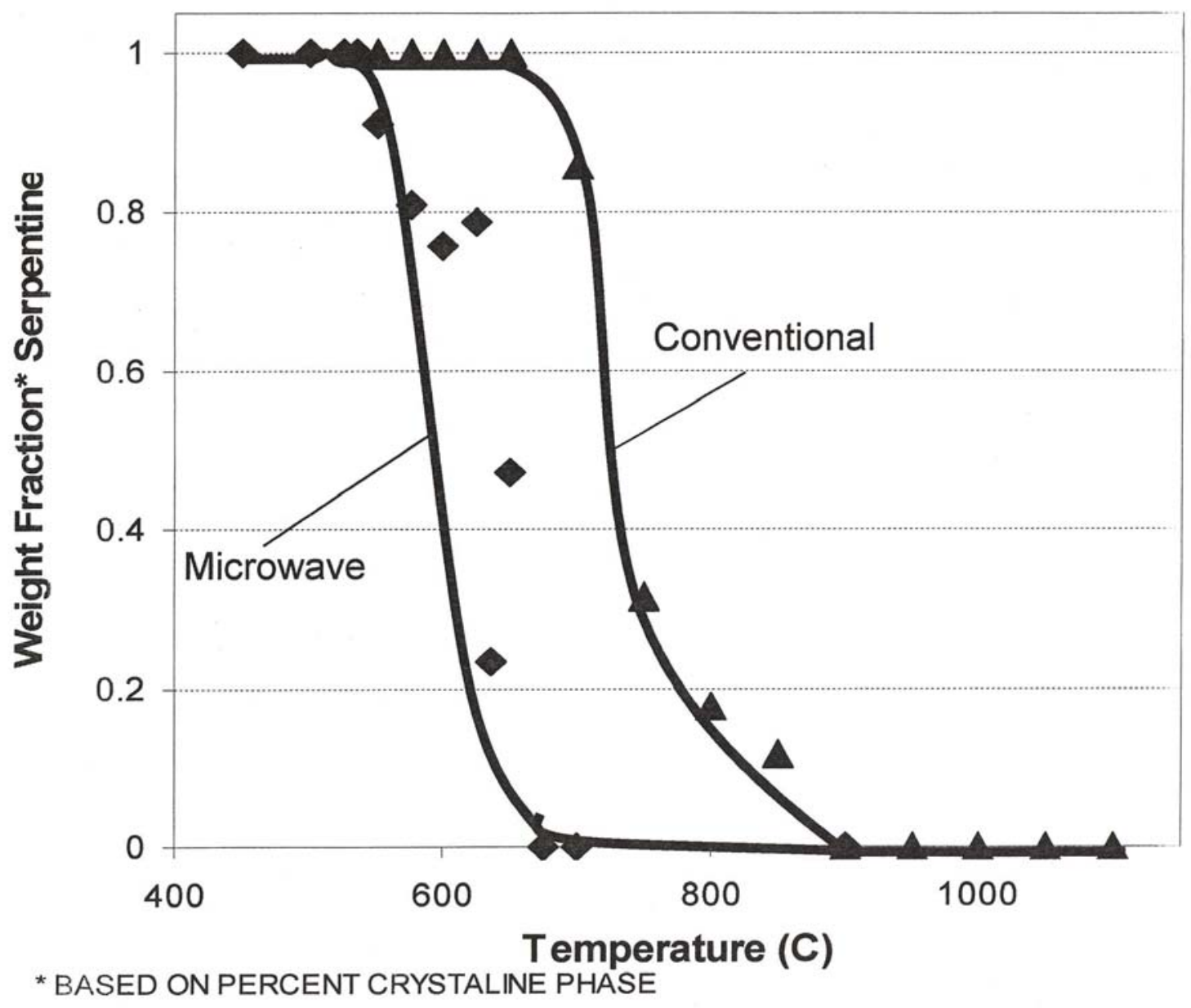

